\title{
Outcome after resuscitation beyond 30 minutes in drowned children with cardiac arrest and hypothermia: Dutch nationwide retrospective cohort study
}

\author{
J K Kieboom, ${ }^{1}$ H J Verkade, ${ }^{1}$ J G Burgerhof, ${ }^{2}$ J J Bierens, ${ }^{3}$ P F van Rheenen, ${ }^{1}$ M C Kneyber, ${ }^{1}$ M J Albers ${ }^{4}$
}

'Department of Paediatrics, Beatrix Children's Hospital, University Medical Centre Groningen, University of Groningen, Netherlands

2Department of Epidemiology University Medical Centre Groningen, University of Groningen, Netherlands

3Van Heurnlaan

10-Anaesthesiology,

Vught, Netherlands

${ }^{4}$ Department of Paediatrics,

St Elizabeth's Hospital, Tilburg, Netherlands

Correspondence to:

J Kieboom j.k.w.kieboom@ umcg.nl

Cite this as: BMJ 2015;350:h418 doi: 10.1136/bmj.h418

Accepted: 13 December 2014

\section{ABSTRACT}

OBJECTIVES

To evaluate the outcome of drowned children with cardiac arrest and hypothermia, and to determine distinct criteria for termination of cardiopulmonary resuscitation in drowned children with hypothermia and absence of spontaneous circulation.

DESIGN

Nationwide retrospective cohort study.

SETTING

Emergency departments and paediatric intensive care units of the eight university medical centres in the Netherlands.

\section{PARTICIPANTS}

Children aged up to 16 with cardiac arrest and hypothermia after drowning, who presented at emergency departments and/or were admitted to intensive care.

\section{MAIN OUTCOME MEASURE}

Survival and neurological outcome one year after the drowning incident. Poor outcome was defined as death or survival in a vegetative state or with severe neurological disability (paediatric cerebral performance category $(P C P C) \geq 4)$.

\section{WHAT IS ALREADY KNOWN ON THIS TOPIC}

Drowned children often experience cardiac arrest with hypothermia, for which prolonged resuscitation has been advocated

Outcome of cardiac arrest with hypothermia in children after drowning is poor, although several case reports describe good neurological outcome after prolonged resuscitation or extracorporeal life support

Several variables correlate with outcome, but so far lack sensitivity to determine important treatment decisions in the emergency department, such as whether or not to continue resuscitation beyond 30 minutes or to start extracorporeal life support

\section{WHAT THIS STUDY ADDS}

Survival with good overall performance or with mild to moderate overall disability occurred in $11 \%$ of children with cardiac arrest and hypothermia who required advanced life support

Resuscitation beyond 30 minutes was performed in more than half of the children in cardiac arrest with hypothermia after drowning, but did not result in a good outcome in any child

Cardiac arrest with hypothermia after drowning in spring, summer, or autumn was associated with poor outcome compared with drowning in winter

The data from this large nationwide cohort question the therapeutic value of resuscitation beyond 30 minutes in children with cardiac arrest and hypothermia after drowning, especially in seasons other than winter

\section{RESULTS}

From 1993 to 2012, 160 children presented with cardiac arrest and hypothermia after drowning. In 98 (61\%) of these children resuscitation was performed for more than 30 minutes $(98 / 160$, median duration 60 minutes), of whom 87 (89\%) died (95\% confidence interval $83 \%$ to $95 \% ; 87 / 98)$. Eleven of the 98 children survived ( $11 \%, 5 \%$ to $17 \%)$, but all had a PCPC score $\geq 4$. In the $62(39 \%)$ children who did not require prolonged resuscitation, $17(27 \%, 16 \%$ to $38 \%)$ survived with a PCPC score $\leq 3$ after one year: $10(6 \%)$ had a good neurological outcome (score 1), five (3\%) had mild neurological disability (score 2), and two (1\%) had moderate neurological disability (score 3 ). From the original 160 children, only 44 were alive at one year with any outcome.

\section{CONCLUSIONS}

Drowned children in whom return of spontaneous circulation is not achieved within 30 minutes of advanced life support have an extremely poor outcome. Good neurological outcome is more likely when spontaneous circulation returns within 30 minutes of advanced life support, especially when the drowning incident occurs in winter. These findings question the therapeutic value of resuscitation beyond 30 minutes in drowned children with cardiac arrest and hypothermia.

\section{Introduction}

Drowning is the primary cause of accidental death in children aged 2-5 throughout the world, with a death rate of three per 100000 per year in developed countries. ${ }^{12}$ In children who do not need any resuscitation or who recovered promptly after basic life support, the neurological prognosis is usually excellent. ${ }^{34}$ The prognosis is much worse in children who did not resuscitate with basic life support. ${ }^{5-8}$

Cardiac arrest in drowned children is often associated with hypothermia. ${ }^{9}$ In such children, guidelines advocate continuation of resuscitation beyond $30 \mathrm{~min}$ utes. $^{1011}$ The rationale is that hypothermia is a potentially reversible cause of cardiac arrest and that hypothermia could exert a protective effect on the brain by slowing its metabolism..$^{11-14}$ Current practice is to continue resuscitation until a core body temperature of $32-34^{\circ} \mathrm{C}$ has been achieved..$^{12}$ This is based on an extensive list of case reports on people with good neurological recovery after prolonged resuscitation for cardiac arrest with hypothermia after drowning, recently reviewed by Tipton and colleagues. ${ }^{15}$ These case reports almost invariably concerned drowning in cold $\left(\leq 6^{\circ} \mathrm{C}\right)$ or icy water. ${ }^{15}$ Drowning in ice water could induce rapid 
cooling, both because of the large temperature gradient and, in the case of hypothermia, induced muscle rigidity and areflexia because of the relative absence of struggle and panic. ${ }^{16}$ It has been suggested that rapid cooling in cold or icy water can exert some protection against anoxia. ${ }^{16}{ }^{17}$ Hypothermia might not only reflect rapid cooling in cold water, however, but also prolonged submersion in warmer water. ${ }^{4}$ Hypothermia in patients on arrival at the emergency department has usually been a sign of poor outcome. ${ }^{18}$ There are, however, no epidemiological data on the relation between water temperature and neurological outcome in children who have drowned with cardiac arrest and hypothermia.

We evaluated the outcome of drowned children with cardiac arrest and hypothermia and determined distinct criteria for termination of cardiopulmonary resuscitation in drowned children with hypothermia without spontaneous return of circulation.

\section{Methods}

\section{Background and setting}

There is an abundance of open water in the Netherlands. Many houses are built near to ponds, ditches, or canals. A temperate maritime climate prevails, with mean air temperatures of $3.5^{\circ} \mathrm{C}$ in winter, $9.5^{\circ} \mathrm{C}$ in spring, $10.6^{\circ} \mathrm{C}$ in autumn, and $17.0^{\circ} \mathrm{C}$ in summer and water temperatures ranging from $0-8^{\circ} \mathrm{C}$ in winter, $6-18^{\circ} \mathrm{C}$ in spring and autumn, and $15-28^{\circ} \mathrm{C}$ in summer..$^{19} 20$

The Dutch emergency medical service has a legally enforced arrival time of less than 15 minutes for medical emergencies. ${ }^{21}$ All ambulance teams consist of a nurse trained in paediatric basic and advanced life support and allowed to perform intubation and administration of adrenaline (epinephrine) in children and a driver trained in paediatric basic life support. In cases of a cardiac arrest, a second emergency medical team is always called on, and, since 1999, this second team is often the helicopter emergency medical service with a physician on board.

Prehospital treatment is provided by emergency medical service nurses according to Dutch national ambulance protocols. These protocols are in accordance with the guidelines of the European Resuscitation Council. The national ambulance protocols instruct that all children with cardiac arrest and hypothermia should be transported, under continuous cardiopulmonary resuscitation, to a hospital with facilities for extracorporeal life support. The physicians of the helicopter emergency medical service and the emergency department treat according to the guidelines of the Dutch Resuscitation Council and the European Resuscitation Council. All children with return of spontaneous circulation after prolonged resuscitation, whether primarily presented at the emergency department of a general hospital or a university medical centre, are transferred to a paediatric intensive care unit in one of the eight university medical centres.

\section{Patients}

We retrospectively identified eligible patients by using the ICD-9 (international classification of diseases, ninth edition) code for drowning (994.1). For those aged 16 and under, their demographical and clinical data were entered in the database when they were admitted at the emergency department, the general paediatric ward, or the paediatric intensive care unit of one of the eight university medical centres from 1 January 1993 to 1 January 2012. Children who presented at the emergency department of a general hospital and transferred to the paediatric intensive care unit were included in this database.

\section{Inclusion and exclusion criteria}

We included children with cardiac arrest after drowning outside (excluding heated outdoor swimming pools) and an initial core body temperature below $34^{\circ} \mathrm{C}$. Drowning outside was an inclusion criterion so we could use season as a proxy for water temperature. As concurrent traumatic injuries could possibly influence outcome, we excluded children who drowned in a traffic or boating incident.

\section{Variables}

The data collection was based on the Utstein style variables for uniform reporting of data from drowning. ${ }^{22}$ Data collected at the arrival of the emergency medical service included initial cardiac arrest rhythm, the use of bag and mask ventilation, intubation, duration of chest compressions, and number of doses of adrenaline and attempts at defibrillation. Data collected at the emergency department included initial core body temperature, score on Glasgow coma scale, the use of bag and mask ventilation, intubation, duration of chest compressions, number of doses of adrenaline, use of extracorporeal life support for cardiac arrest, and return of spontaneous circulation or death. Data collected at the paediatric intensive care unit included death or discharge, the cause of death, and, if applicable, the withdrawal of life sustaining treatment. Final disposition was dead or alive at one year after the drowning incident, and, if alive, the neurological status according to the paediatric cerebral performance category score (PCPC). ${ }^{23}$

\section{Definitions}

The minimum and maximum durations of submersion were taken from the medical records and were based on estimations by the caretaker(s) of the child at the time of incident. Cardiac arrest was defined as the necessity for chest compressions on arrival of the emergency medical service or and/or helicopter emergency medical service. The start point of the resuscitation time was marked by the initiation of chest compressions by the emergency services and the total duration of resuscitation included prehospital and in hospital advanced life support but excluded bystander cardiopulmonary resuscitation. Prolonged resuscitation was defined as more than 30 minutes of total resuscitation. This cut off was chosen because the mean attempted resuscitation time in many studies concerning resuscitation in children with out of hospital cardiac arrest averaged 30 minutes. ${ }^{24}$ We defined spring as the period between 1 March and 31 May, summer between 1 June and 31 August, autumn 
between 1 September and 30 November, and winter between 1 December and 29 February.

Initial cardiac arrest rhythm was the first rhythm visible after connection of the patient to the electrocardiograph of the emergency medical services. Initial temperature was defined as the first body temperature measured within one hour after arrival at the emergency department and concerned measurements of rectal or oesophageal temperature with a low reading thermometer. The initial blood gas analysis was measured within two hours after arrival at the emergency department. The term extracorporeal life support was used to indicate both extracorporeal circulation and extracorporeal membrane oxygenation. In the paediatric intensive care unit a diagnosis of severe neurological damage could lead to withdrawal of further intensive treatment. The severity of the brain damage was assessed by clinical neurological examination, cerebral magnetic resonance imaging and/or electroencephalography, and/or sensory evoked potentials. The combined results could lead to a decision to withdraw further intensive treatment. The paediatric cerebral performance category scale (PCPC) ${ }^{23}$ was used to qualify neurological outcome. This scale rates the neurological outcome by cognitive impairment in six categories: good neurological performance, mild neurological disability, moderate neurological disability, severe neurological disability, coma or vegetative state, and brain death. ${ }^{23}$ A good outcome was characterised by a PCPC score $\leq 3$ at one year after the incident. Although it can be debated whether patients with a score of 3, who will require assistance in daily activities, really have a good outcome, we chose this conservative cut off point to be able to classify extremely poor outcome beyond discussion. We therefore defined poor outcome as death or

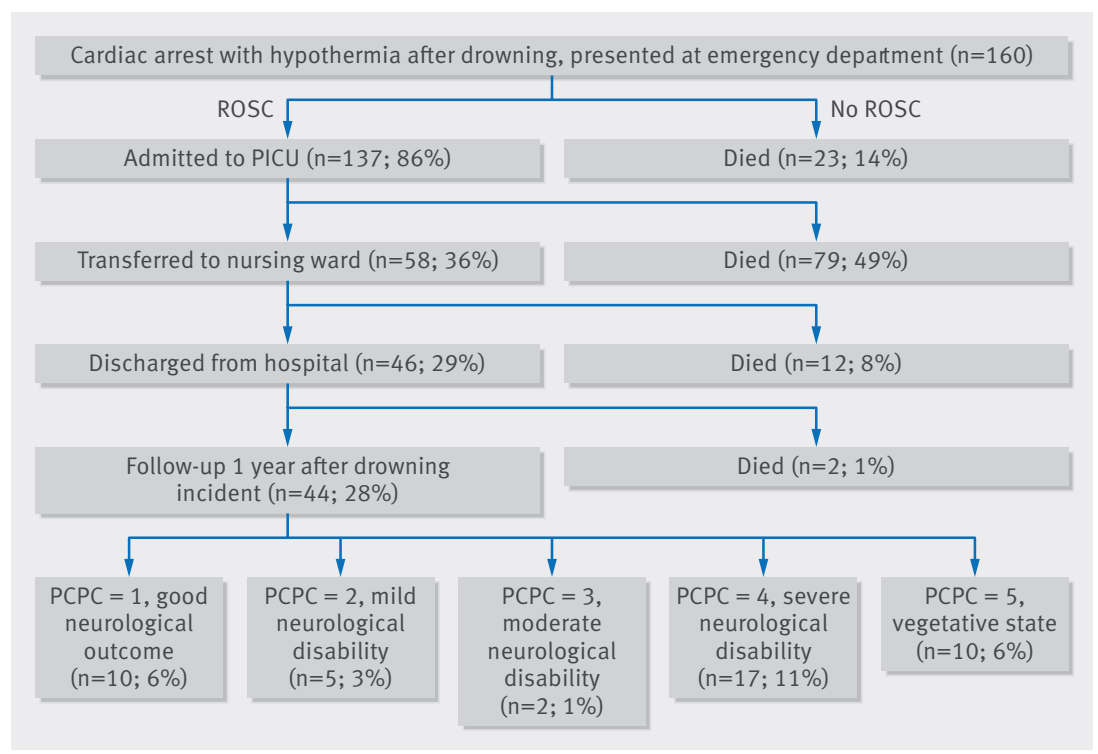

Fig 1 | Patient flow and clinical outcome of children who drowned with cardiac arrest and hypothermia after presentation at emergency department. Final outcome was one year after drowning incident and categorised with paediatric cerebral performance categories $(P C P C)$. Death, vegetative state, and severe disability were categorised as poor outcome. ROSC $=$ return of spontaneous circulation, $\mathrm{PICU}=$ paediatric intensive care unit survival with severe neurological disability at one year after the incident (score $\geq 4)$.

\section{Statistical analyses}

Continuous data are presented as medians and interquartile range. Dichotomous and categorical data are presented as proportions, percentages of total, and 95\% confidence intervals. We used Fisher's exact test for categorical data and Mann-Whitney U test for continuous data. $\mathrm{P}<0.05$ was considered significant. The odds ratios are presented with $95 \%$ confidence interval. We used IBM SPSS statistics version 22 for the analyses.

\section{Results}

\section{Description of study population}

From 1993 to 2012, 784 children were identified by the ICD-9 code for drowning. Two of the eight university medical centres were unable to identify children who died at the emergency department. Medical records were available for 753 children. Seventeen children were misclassified, thus 736 children were retained in the database, of whom 207 (28\%) experienced cardiac arrest requiring advanced life support. Of these 207 children, 47 (47/207, 23\%) were excluded from the present study: 25 had an initial body temperature of $\geq 34^{\circ} \mathrm{C}$, 14 were involved in a vehicle or boat incident, and eight drowned indoors.

We concentrated on the 160 children who experienced a cardiac arrest with hypothermia after drowning outside, which was not associated with a motor vehicle or boat incident. Figure 1 shows the flow of the 160 included children from the emergency department onwards and their subsequent clinical outcome. Of these children, 104 (65\%) had ongoing cardiac arrest on arrival at the emergency department. All 98 children in whom return of spontaneous circulation was not achieved within 30 minutes received prolonged resuscitation. Of these 98 children, 23 children died in the emergency department. The 137 other children, in whom return of spontaneous circulation was achieved, were admitted to the paediatric intensive care unit (137/160, 86\%), where 79 died (79/137; 58\%, $95 \%$ confidence interval 50\% to $66 \%$ ); 30 had a diagnosis of brain death (30/79; 38\%, 27\% to 49\%) and 27 had a diagnosis of severe neurological damage (27/79; $34 \%, 24 \%$ to $44 \%$ ), the 22 others died of cardiac arrest, acute respiratory distress syndrome, or multi-organ failure $(22 / 79 ; 28 \%, 18 \%$ to $38 \%)$. In the original 160 children, the total mortality rate after cardiac arrest with hypothermia was $73 \%(66 \%$ to $80 \%$; $n=116)$. Ten children remained in a vegetative state (10/160; $6 \%$, $2 \%$ to $10 \%$ ), and 17 had severe neurological damage (17/160; $11 \%, 6 \%$ to $16 \%)$. One year after the drowning accident 17 children had a PCPC score of $\leq 3$ (17/160; $11 \%, 6 \%$ to $16 \%$ ).

Figure 2 shows that most incidents of drowning in children with cardiac arrest and hypothermia occurred in summer. Tables 1, 2, and 3 describe the basic characteristics of the children and the parameters correlated to outcome. 


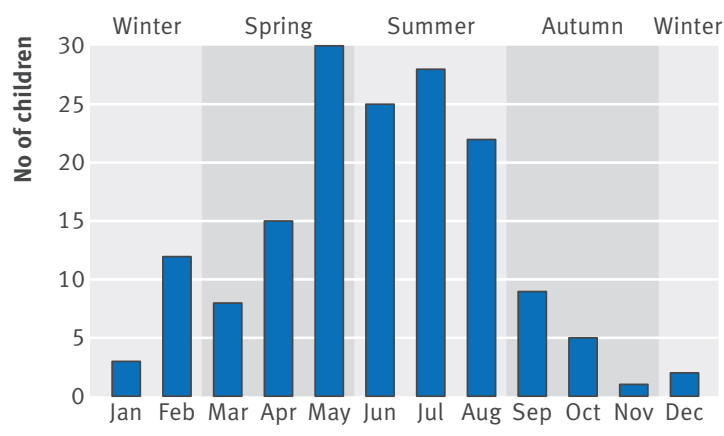

Month of drowning

Fig 2 | Distribution of children who drowned with cardiac arrest and hypothermia by month and season

\begin{tabular}{|c|c|}
\hline Characteristic & Data \\
\hline Boys & $117(73)$ \\
\hline Median (IQR) age (years) & $2(1-3)$ \\
\hline \multicolumn{2}{|l|}{ Distribution of age (years): } \\
\hline 0 & $2(1)$ \\
\hline 1 & $52(33)$ \\
\hline 2 & $40(25)$ \\
\hline 3 & $29(18)$ \\
\hline 4 & $16(10)$ \\
\hline 5 & $6(4)$ \\
\hline $6-10$ & $10(6)$ \\
\hline $11-16$ & $5(3)$ \\
\hline \multicolumn{2}{|l|}{ Body of water $(n=156)$ : } \\
\hline Ditch & $75(47)$ \\
\hline Garden pond & $39(24)$ \\
\hline Swimming pool & $14(9)$ \\
\hline River & $12(8)$ \\
\hline Lake & $9(6)$ \\
\hline Sea & $4(3)$ \\
\hline Other & $3(2)$ \\
\hline \multicolumn{2}{|l|}{ Season: } \\
\hline Summer & $75(47)$ \\
\hline Spring/autumn & $68(43)$ \\
\hline Winter & $17(11)$ \\
\hline
\end{tabular}

\section{Prolonged resuscitation}

Prolonged resuscitation was performed in 98 of the 160 children with a cardiac arrest and hypothermia (61\%, $95 \%$ confidence interval $54 \%$ to $69 \%$ ). The outcome was not good in any of the children who underwent resuscitation beyond 30 minutes ( $0 \%$ with good outcome, $0 \%$ to $3 \%$ ) (fig 3). Seventeen of the children who did not require prolonged resuscitation survived with a PCPC score $\leq 3$ after one year (17/62 good outcome; $27 \%, 16 \%$ to $38 \%$ ). The maximum duration of resuscitation with good outcome was 25 minutes. The outcome of prolonged resuscitation was extremely poor: 87 of the 98 children died $(89 \%, 83 \%$ to $95 \%)$, and 11 survived in a vegetative state or with severe neurological damage (11\%, 5\% to $17 \%)$. Table 4 shows the characteristics of the children in relation to duration of resuscitation. Extracorporeal life support was performed in 12 children, of whom 11 died and one survived in a vegetative state. Thus, no child who underwent prolonged resuscitation, with or without extracorporeal life support, had a good outcome.

\section{Season}

Season correlated strongly with outcome (fig 4). Children who drowned in winter had a significantly better outcome than those who drowned in other seasons (5/17, 29\% (95\% confidence interval $8 \%$ to $51 \%$ ) $v 12 / 143$, $8 \%$ ( $4 \%$ to $13 \%$ ); odds ratio 4.6 (1.4 to 15.1$), \mathrm{P}=0.013$ ). This seasonal effect was also evident in children who underwent resuscitation for less than 30 minutes: all five children who drowned in winter had a good outcome compared with 12 of the 57 children who drowned in other seasons $(5 / 5,100 \%$ (55\% to $100 \%) v 12 / 57,21 \%$ ( $10 \%$ to $32 \%$ ); odds ratio 4.8 (2.9 to 7.9$), \mathrm{P}=0.01$ ). The median estimated minimum and maximum durations of submersion were not different for winter and other seasons (fig 5). The initial core body temperature was significantly lower in children who drowned in winter than in other seasons (difference $3.7^{\circ} \mathrm{C}, \mathrm{P}<0.001$; fig 5).

\section{Initial cardiac arrest rhythm}

We were able to retrieve data on the initial cardiac arrest rhythm from the medical records in 118 of the 160 children (74\%). Asystole was diagnosed in nearly all children $(101 / 118,86 \%)$, followed by bradycardia

\begin{tabular}{|c|c|c|c|c|c|}
\hline & No of children & $\begin{array}{l}\text { No }(\%, 95 \% \mathrm{Cl}) \text { with good } \\
\text { outcome }\end{array}$ & $\begin{array}{l}\text { No }(\%, 95 \% \mathrm{Cl}) \text { with poor } \\
\text { outcome }\end{array}$ & OR $(95 \% \mathrm{Cl})$ & $P$ value \\
\hline Number of children & 160 & $17(11,6$ to 15$)$ & $143(89,85$ to 94$)$ & - & - \\
\hline \multicolumn{6}{|c|}{ Total duration of advanced life support (minutes): } \\
\hline$\leq 30$ & $62(39 \%)$ & $17(27,16$ to 39$)$ & $45(73,61$ to 84$)$ & - & $<0.001$ \\
\hline$>30$ & $98(61 \%)$ & $0(0,0$ to 3$)$ & $98(100,97$ to 100$)$ & & \\
\hline \multicolumn{6}{|l|}{ Season: } \\
\hline Winter & $17(11 \%)$ & $5(29,8$ to 51$)$ & $12(71,49$ to 92$)$ & $4.55(1.37$ to 15.09$)$ & 0.008 \\
\hline Other seasons & $143(89 \%)$ & $12(8,4$ to 13$)$ & $131(92,87$ to 96$)$ & & \\
\hline \multicolumn{6}{|l|}{ Initial cardiac arrest rhythm: } \\
\hline No of children with data & 118 & 14 & 104 & - & - \\
\hline Asystole & $101(86 \%)$ & $8(8,3$ to 13$)$ & $93(92,87$ to 97$)$ & 0.13 (0.04 to 0.46$)$ & 0.001 \\
\hline Bradycardia & $15(13 \%)$ & $6(40,15$ to 65$)$ & $9(60,35$ to 85$)$ & & \\
\hline Ventricular fibrillation & $2(2 \%)$ & $0(0,0$ to 66$)$ & $2(100,34$ to 100$)$ & - & - \\
\hline
\end{tabular}




\begin{tabular}{|c|c|c|c|c|c|}
\hline & Total & $\begin{array}{l}\text { No }(\%, 95 \% \mathrm{Cl}) \text { or median } \\
\text { (IQR) with good outcome }\end{array}$ & $\begin{array}{l}\text { No }(\%, 95 \% \mathrm{Cl}) \text { or median } \\
\text { (IQR) with poor outcome }\end{array}$ & OR $(95 \% \mathrm{Cl})$ & P value \\
\hline No of children & 160 & $17(11 \%, 6$ to 15$)$ & $143(89 \%, 85$ to 94$)$ & - & - \\
\hline \multicolumn{6}{|l|}{ Drowning event } \\
\hline \multicolumn{6}{|l|}{ Median estimated duration of submersion (IQR): } \\
\hline Minimal (min) & $13(10-20), n=130$ & $9(5-10), n=14$ & $15(10-24), n=116$ & $0.85(0.75 \text { to } 0.96)^{\star}$ & 0.009 \\
\hline Maximal (min) & $20(15-40), n=105$ & $13(9-19), n=12$ & 20 (15-43), n=93 & $0.89(0.82 \text { to } 0.98)^{\star}$ & 0.02 \\
\hline \multicolumn{6}{|l|}{ Basic life support at scene: } \\
\hline Performed & $124 / 134(93 \%)$ & $16(94,83$ to 100$)$ & $108 / 117(92,87$ to 97$)$ & - & 0.79 \\
\hline \multicolumn{6}{|l|}{ Delayed: } \\
\hline No delay & $100 / 124(81 \%)$ & $14 / 16(88,71$ to 100$)$ & $86 / 108(80,72$ to 87$)$ & - & 0.46 \\
\hline$\leq 10 \min$ & $20 / 124(16 \%)$ & 2/16 (13, 0 to 29$)$ & $18 / 108(17,10$ to 24$)$ & & \\
\hline$>10 \min$ & 4/124 (3\%) & $0 / 16(0,0$ to 17$)$ & $4 / 108(4,0$ to 7$)$ & & \\
\hline \multicolumn{6}{|l|}{ Emergency medical service } \\
\hline Bag and mask ventilation & $159 / 159(100 \%)$ & $17(100,84$ to 100$)$ & $142 / 142(100,98$ to 100$)$ & - & - \\
\hline Endotracheal intubation & $133 / 153(87 \%)$ & $11(65,42$ to 87$)$ & $122 / 136(90,85$ to 95$)$ & 0.25 (0.08 to 0.83$)$ & 0.02 \\
\hline Adrenaline & $124 / 139(89 \%)$ & $9 / 15(60,35$ to 85$)$ & $115 / 124(93,88$ to 97$)$ & $0.12(0.03$ to 0.40$)$ & 0.01 \\
\hline Defibrillation & $18 / 120(15 \%)$ & 0/14 (0, 0 to 19$)$ & $18 / 106(17,10$ to 24$)$ & - & 0.13 \\
\hline \multicolumn{6}{|l|}{ Emergency department } \\
\hline Ongoing ALS at ED & $104(65 \%)$ & $1(1,0$ to 3$)$ & $103(99,97$ to 100$)$ & $0.02(0.00$ to 0.19$)$ & $<0.001$ \\
\hline Median (IQR) initial core body temperature $\left({ }^{\circ} \mathrm{C}\right)$ & $29.8(28.0-31.9)$ & $29.0(26.3-31.0)$ & $29.8(28.0-32.0)$ & - & 0.39 \\
\hline Median (IQR) initial GCS & $3(3-3)$ & $4(3-5)$ & $3(3-3)$ & $0.19(0.09$ to 0.43$) \dagger$ & $<0.001$ \\
\hline \multicolumn{6}{|l|}{ Initial blood gas analysis: } \\
\hline Median (IQR) pH & $6.74(6.53-6.90), n=135$ & $6.90(6.80-7.00), n=13$ & $6.70(6.50-6.87), n=122$ & $0.56(0.39$ to 0.81$) \neq$ & $<0.001$ \\
\hline Median (IQR) negative BE (mmol/l) & $28(23-31), n=106$ & $22(18-24), n=11$ & $28(24-32), n=95$ & $0.80(0.69$ to 0.92$)$ & $<0.001$ \\
\hline Median $(\mathrm{IQR}) \mathrm{pCO}_{2}(\mathrm{kPa})$ & $8.1(4.8-14.0), n=126$ & $7.6(4.2-8.5), n=11$ & $8.1(4.9-15.0), n=115$ & - & 0.08 \\
\hline Median (IQR) total duration of ALS (min) & $45(20-75)$ & $10(5-15)$ & $50(30-80)$ & $0.82(0.74 \text { to } 0.92)^{\star}$ & $<0.001$ \\
\hline Median (IQR) total doses of adrenaline & $3(2-6), n=88$ & $1(0-3), n=13$ & $4(2-7), n=75$ & $0.65(0.47$ to 0.89$) \S$ & 0.01 \\
\hline Extracorporeal life support & $12(8 \%)$ & $0(0,0$ to 22$)$ & $12(100,78$ to 100$)$ & - & $<0.001$ \\
\hline $\begin{array}{l}\text { IQR }=\text { interquartile range, } A L S=\text { advanced life suppor } \\
\text { *Per } 1 \text { min increase. } \\
\text { †Per } 1 \text { decrease. } \\
\text { †Per } 0.1 \text { decrease. } \\
\text { \$Per dose. }\end{array}$ & $\mathrm{ED}=$ emergency department, $\mathrm{C}$ & $5=$ Glasgow coma scale score, $\mathrm{B}$ & $=$ base excess. & & \\
\hline
\end{tabular}

$(15 / 118,13 \%)$ and ventricular fibrillation $(2 / 118,2 \%)$. Bradycardia correlated strongly with good outcome: six of the 15 children with bradycardia had good outcome versus eight of the 101 children with asystole $(40 \%$ ( $95 \%$ confidence interval $15 \%$ to $65 \%$ ) $v 8 \%(3 \%$ to $13 \%$ ); odds ratio 7.8 (2.2 to 27.3), $\mathrm{P}=0.001$ ).

Duration of submersion, doses of adrenaline, and blood gas abnormalities

In only $3 \%$ of the cases $(5 / 160)$ was the drowning incident witnessed by an adult, and consequently the

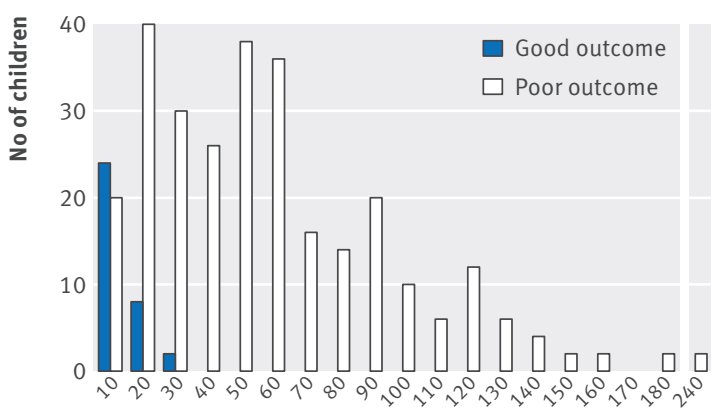

Duration of advanced life support (mins)

Fig 3 Outcome in drowned children with cardiac arrest and hypothermia according to duration of advanced life support duration of submersion was not precisely known in most cases. The typical history of most incidents was a sudden realisation of the child's absence, followed by an immediate search by the caretaker. Though the duration of the search was reasonably well known, it was usually unknown how long the child had been out of sight. The median estimated minimum and maximum durations of submersion correlated negatively with outcome (Table 3). The longest estimated duration of submersion with good outcome was 25 minutes. Fig 6 shows the relation between maximum estimated submersion duration and outcome.

The median total number of doses of adrenaline administered was negatively associated with outcome (Table 3). The median initial $\mathrm{pH}$ and the base excess were significantly lower in children with poor outcome (table 3). All children were manually or mechanically ventilated at the time of the initial blood gas measurement, while some children were still being resuscitated and others already had return of spontaneous circulation. The lowest $\mathrm{pH}$ associated with good a outcome was 6.75 .

\section{Treatment changes}

We performed a subanalysis to determine whether changes in treatment during the study period affected 


\begin{tabular}{|c|c|c|c|c|}
\hline & $\begin{array}{l}\text { No }(\%, 95 \% \mathrm{Cl}) \text { or median (IQR) } \\
\text { with ALS } \leq 30 \text { minutes }\end{array}$ & $\begin{array}{l}\text { No }(\%, 95 \% \mathrm{CI}) \text { or median (IQR) } \\
\text { with ALS }>30 \text { minutes }\end{array}$ & OR $(95 \% \mathrm{Cl})$ & $P$ value \\
\hline No of children & $62(39,31$ to 46$)$ & $98(61,54$ to 69$)$ & - & - \\
\hline \multicolumn{5}{|l|}{ Drowning event } \\
\hline \multicolumn{5}{|l|}{ Season: } \\
\hline Winter & $5(29,8$ to 51$)$ & $12(71,49$ to 92$)$ & - & 0.41 \\
\hline Other seasons & $57(40,32$ to 48$)$ & $86(60,52$ to 68$)$ & & \\
\hline \multicolumn{5}{|l|}{ Median estimated submersion duration (IQR): } \\
\hline Minimal (min) & $10(5-15), n=50$ & $15(10-30), n=80$ & $1.08(1.03 \text { to } 1.23)^{\star}$ & $<0.01$ \\
\hline Maximal (min) & $15(10-22), n=41$ & $28(15-45), n=64$ & $1.04(1.01 \text { to } 1.07)^{\star}$ & $<0.01$ \\
\hline Basic life support performed at scene & $52 / 56(93,86$ to 100$)$ & $72 / 78(92,86$ to 98$)$ & - & 1.0 \\
\hline \multicolumn{5}{|l|}{ Emergency medical service } \\
\hline \multicolumn{5}{|l|}{ Initial cardiac arrest rhythm: } \\
\hline Asystole & $35(35,25$ to 44$)$ & $66(65,56$ to 75$)$ & - & 0.07 \\
\hline Bradycardia & $9(60,35$ to 85$)$ & $6(40,15$ to 65$)$ & & \\
\hline Ventricular fibrillation & $2(100,22$ to 100$)$ & $0(0,0$ to 78$)$ & - & - \\
\hline Endotracheal intubation & $49 / 59(83,73$ to 93$)$ & $84 / 93(90,84$ to 96$)$ & - & 0.21 \\
\hline Adrenaline & $42 / 54(78,67$ to 89$)$ & $82 / 85(96,93$ to 100$)$ & 7.81 (2.09 to 29.20$)$ & $<0.01$ \\
\hline Defibrillation & $6 / 51(12,3$ to 21$)$ & $12 / 69(17,8$ to 26$)$ & - & 0.45 \\
\hline \multicolumn{5}{|l|}{ Emergency department } \\
\hline Ongoing ALS at ED & $12(19,10$ to 29$)$ & $92(94,89$ to 99$)$ & - & - \\
\hline Median (IQR) initial core body temperature $\left({ }^{\circ} \mathrm{C}\right)$ & $30.4(28.9-32.2)$ & $29.0(27.0-31.7)$ & $1.16(1.03$ to 1.31$) \dagger$ & $<0.01$ \\
\hline \multicolumn{5}{|l|}{ Initial blood gas analysis: } \\
\hline Median $(\mathrm{IQR}) \mathrm{pH}$ & $6.86(6.75-6.97), n=53$ & $6.58(6.47-6.81), n=82$ & $1.74(1.41$ to 2.16$) \ddagger$ & $<0.01$ \\
\hline Median (IQR) negative BE (mmol/L) & $26(21-29), n=47$ & $28(25-33), \mathrm{n} 59$ & $1.13(1.05$ to 1.22$) \S$ & $<0.01$ \\
\hline Median $(\mathrm{IQR}) \mathrm{pCO}_{2}(\mathrm{kPa})$ & $6.1(4.3-8.6), n=50$ & $10.9(6.2-17.0), n=76$ & $1.22(1.13$ to 1.34$)$ I & $<0.01$ \\
\hline Median (IQR) total duration of ALS (min) & $15(10-25)$ & $60(45-90)$ & - & - \\
\hline Median (IQR) total doses of adrenaline & $2(1-3), n=45$ & $6(4-8), n=43$ & $1.82(1.41$ to 2.34$)$ & $<0.01$ \\
\hline Extracorporeal life support & $0(0,0$ to 5$)$ & $12(12,6$ to 19$)$ & - & - \\
\hline \multicolumn{5}{|l|}{ Outcome } \\
\hline Death & $29(47 \%, 34$ to 59$)$ & $87(89 \%, 83$ to 95$)$ & 9.00 (4.04 to 20.06) & $<0.01$ \\
\hline Vegetative state (PCPC 5) & $5(8 \%, 1$ to 15$)$ & $5(5 \%, 1$ to 9$)$ & - & 0.51 \\
\hline Severe damage (PCPC 4) & $11(18 \%, 8$ to 27$)$ & $6(6 \%, 1$ to 11$)$ & 0.30 (0.11 to 0.87$)$ & 0.03 \\
\hline Mild-moderate damage (PCPC 2-3) & $7(11 \%, 3$ to 19$)$ & $0(0 \%, 0$ to 3$)$ & 0.89 (0.81 to 0.97$)$ & $<0.01$ \\
\hline No damage (PCPC 1) & $10(16 \%, 7$ to 25$)$ & $0(0 \%, 0$ to 3$)$ & $0.84(0.75$ to 0.94$)$ & $<0.01$ \\
\hline $\begin{array}{l}\text { IQR }=\text { interquartile range, } E D=\text { emergency departmer } \\
\text { *Per } 1 \text { min increase. } \\
\text { †Per } 1^{\circ} \mathrm{C} \text { decrease } \\
\text { ‡Per } 0.1 \text { decrease } \\
\text { §er } 1 \mathrm{mmol} \text { decrease. } \\
\text { १Per } 1 \mathrm{kPa} \text { increase. }\end{array}$ & $=$ base excess, $P C P C=$ paediatric cereb & erformance category. & & \\
\hline
\end{tabular}

the main outcomes. The percentage of children with good outcome in the first five years of the study period was comparable with the percentage in the last five years (7/51, 14\% (95\% confidence interval 4\% to $23 \%$ ) $v$ 5/30, $17 \%$ (3\% to $30 \%), \mathrm{P}=0.75)$.

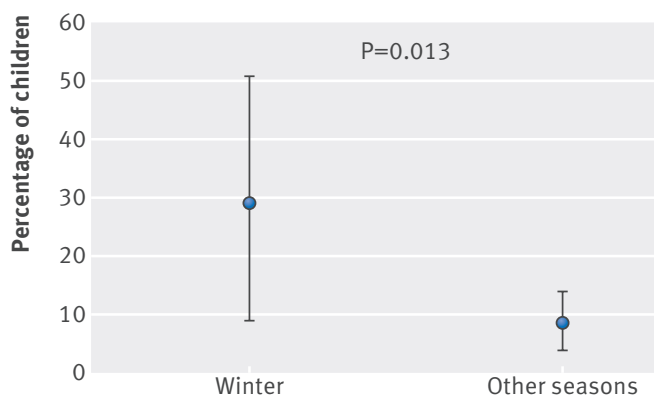

Fig 4 | Proportion of children with good outcome of cardiac arrest and hypothermia after drowning according to season (as proxy for water temperature)

\section{Discussion}

Implication of key findings

In children with cardiac arrest and hypothermia after drowning the necessity for resuscitation for more than 30 minutes did not result in good outcome in any child: $89 \%$ of children died and $11 \%$ survived in a vegetative state or with severe neurological damage. The study used a nationwide database over the period 1993-2012. Most children drowned during spring, summer, or autumn and had a much poorer outcome than those who drowned in winter. These results strongly question the therapeutic value of prolonged resuscitation in drowned children with cardiac arrest and hypothermia.

\section{Strengths and weaknesses}

To our knowledge this is the largest study that has evaluated outcome of cardiac arrest with hypothermia in children after drowning. The cohort included all children who had been admitted after drowning to one of 

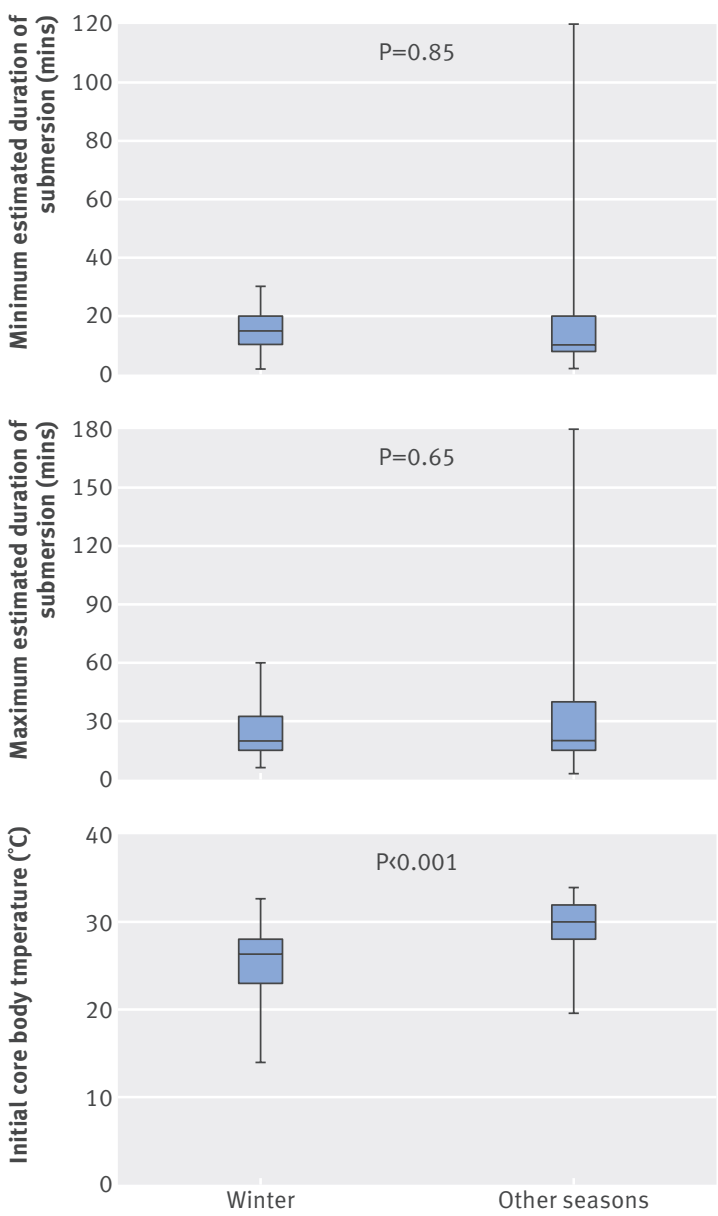

Fig 5 Estimated minimum and maximum durations of submersion and initial core body temperature in drowned children with cardiac arrest and hypothermia according to season (as proxy for water temperature)

the eight Dutch university medical centres in 1993-2012. In the Netherlands it is common practice to transfer all mechanically ventilated children to a paediatric intensive care unit. It therefore seems unlikely that we missed any children with a good outcome after prolonged resuscitation. Theoretically it is possible that we missed children who showed such a rapid and full recovery after a cardiac arrest with hypothermia that transfer to intensive care was not indicated; this seems

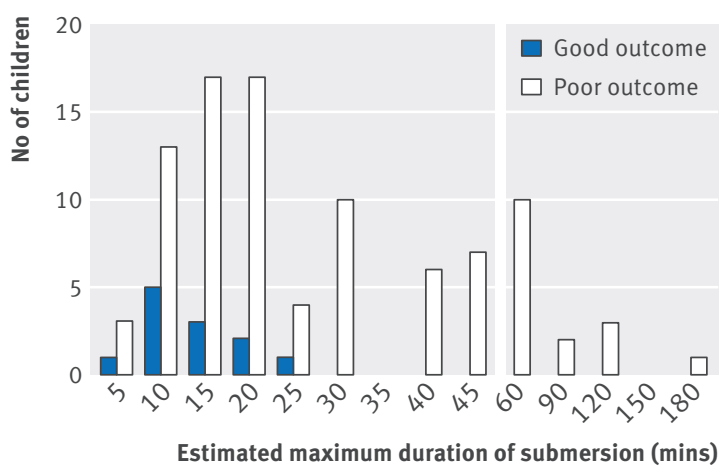

Fig 6 | Estimated maximum duration of submersion and outcome in drowned children with cardiac arrest and hypothermia

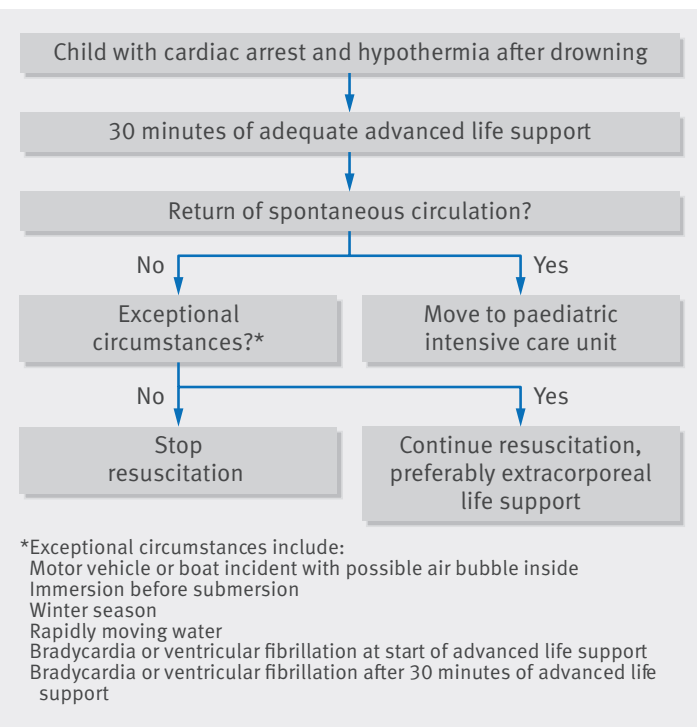

Fig 7 | Proposed decision tree for continuation of resuscitation beyond 30 minutes in children with cardiac arrest and hypothermia (core body temperature $<34^{\circ} \mathrm{C}$ ) after drowning outside in temperate climate

improbable after prolonged resuscitation. Two other categories of children who drowned could have been missed-namely, those presented at a general hospital and in whom spontaneous circulation never returned and those who died in the emergency department of two of the eight university medical centres. Nevertheless, this would not have undermined the main findings; inclusion of these children would have resulted in an even more unfavourable outcome.

As this study pertains to a setting with excellent emergency medical services, it might not be possible to extrapolate the results to settings with limited resources. The extremely poor prognosis in circumstances with excellent healthcare provisions, however, does not offer much hope for the prognosis in areas with less developed or less available emergency medical services.

Our study is retrospective, with the inherent methodological limitations. By using the ICD-9 code for drowning we might not have identified all children. Because an underlying cause is rare in drowning in children, however, the risk of misclassification seems limited. The fact that most children drowned in stagnant water (such as ponds and most ditches) might raise the question of possible contamination influencing the final outcome. Sepsis or meningitis, however, was not observed in this cohort. Although it would have been more accurate to correlate outcome with exact water temperature, temperatures were not available for the small bodies of water in which most children drowned. Instead, we used season as a proxy for water temperature. As we carried out this study in a temperate climate, "season" cannot be simply extrapolated to other parts of the world. The indicated range of water temperatures during the Dutch seasons, however, could help with translating our findings to other climates. Finally, guidelines for the treatment of paediatric 
cardiac arrest and cardiac arrest with hypothermia changed during the 19 year period of our study. Despite these changes, the percentage of children with good outcome in the first five years of the study period was comparable with that in the last five years.

\section{Comparison with other studies}

In children with cardiac arrest after drowning, neurologically intact survival varies from $0 \%$ to $40 \% .^{825-28}$ The most recent study reported a neurologically favourable outcome in only $4.4 \%$ of children. ${ }^{8}$ The percentage in that study could have been because of the low rate of bystander cardiopulmonary resuscitation, in contrast with our study, and the fact that the emergency medical services were not allowed to perform advanced life support in children. ${ }^{82}$ In the Netherlands both the emergency medical services and helicopter emergency medical service are adequately trained and certified in paediatric advanced life support.

Prolonged resuscitation has been advocated in patients with cardiac arrest and hypothermia. ${ }^{10} 30$ Its importance has been well established for patients with accidental hypothermic cardiac arrest without asphyxia. ${ }^{12} 133132$ In contrast, an asphyxia-related cause of cardiac arrest with hypothermia has been identified as the most predictive factor for death. ${ }^{33}$ This urges the need for prognostic factors that could help to identify children who might benefit from prolonged resuscitation. In our study, however, we found no beneficial effect from prolonged resuscitation in any child. The high percentage of return of spontaneous circulation after prolonged resuscitation suggests that in children the hypoxic heart is capable of restoring function, but the extremely poor outcome suggests that the brain has already sustained severe damage. ${ }^{29}$ Drowning in icy or cold water might be associated with good neurological outcome. ${ }^{15}$ Despite the fact that none of the 12 children who received prolonged resuscitation after drowning in winter had good outcome, the $95 \%$ confidence interval for this group, based on such a small sample, extends to a survival rate of $22 \%$. We cannot, therefore, exclude a beneficial effect of prolonged resuscitation in a substantial fraction of children who drown in winter. As most childhood drowning incidents occur in non-icy water, ${ }^{4734}$ the observation that prolonged resuscitation was futile in children with cardiac arrest and hypothermia after drowning in other seasons is important. Slow body cooling in warmer water could explain this poor outcome. ${ }^{31}$ An initial core body temperature of less than $34^{\circ} \mathrm{C}$ would probably indicate a longer duration of submersion when the water temperature is higher. Accordingly, moderate to severe hypothermia after drowning in seasons other than winter probably reflects a long duration of submersion associated with severe asphyxia. ${ }^{35}$ Duration of submersion is the predominant factor in determining outcome of drowning. ${ }^{4} 1836$ Theoretically, the influence of the season of drowning on the outcome in the present study could be related to differences in duration of submersion. The median estimated durations of submersion, however, were not different for winter and the other seasons. Importantly, the accuracy of the estimations of duration was limited because of the lack of witnesses. Thus, there might be an additional impact of a neuroprotective effect of rapid body cooling after drowning in ice cold water. ${ }^{12} 1531$ Previous studies have not established the influence of water temperature on outcome. ${ }^{41836}$ These studies included people who recovered spontaneously or after basic life support after drowning, and therefore the results are difficult to compare because our cohort consisted solely of children with cardiac arrest who required advanced life support. Our findings seem in accordance with anoxia by another mechanismnamely, avalanches. People in avalanches with cardiac arrest caused by hypothermia have a good prognosis compared with people in avalanches with cardiac arrest caused by asphyxia and subsequent hypothermia. ${ }^{37}$

Our study shows that survival with good neurological outcome is unlikely for children who experience cardiac arrest with hypothermia after drowning in seasons other than winter, and who remain in asystole after 30 minutes of adequate advanced life support.

Previously reported risk factors for poor outcome after drowning include duration of submersion, 591838 asystole at the initial assessment by the emergency medical services, ${ }^{39}$ number of doses of adrenaline, ${ }^{7}$ initial $\mathrm{pH},{ }^{70}$ and Glasgow coma score at the emergency department. ${ }^{54142}$ The number of doses of adrenaline, the initial $\mathrm{pH}$, and the coma score were associated with outcome, but all could be regarded as indicators of prolonged resuscitation. Asystole as the initial cardiac arrest rhythm correlated significantly with poor outcome. The duration of submersion could be estimated in only $75 \%$ of the children, and this information was often not available in the emergency department. Compared with other studies, we found no correlation between sex and age and outcome. ${ }^{7} 3940$

\section{Importance of study}

Our findings challenge the current recommendation for prolonged resuscitation in children with cardiac arrest and hypothermia after drowning. ${ }^{10}{ }^{11}$ We propose a decision tree to be used in children experiencing cardiac arrest with hypothermia after drowning outside in a temperate climate (fig 7). The current data provide support for a strategy to refrain from continuation of resuscitation beyond 30 minutes in children with an initial core body temperature $<34^{\circ} \mathrm{C}$ after drowning in seasons other than winter and asystole as the initial cardiac arrest rhythm. It is important to emphasise, however, that this strategy is not advocated in children in whom hypothermia possibly preceded asphyxia or in whom hypothermia occurred rapidly. Such exceptional circumstances could be drowning in a motor vehicle or boat incident with a possible air bubble inside, ${ }^{15}$ being immersed before drowning, ${ }^{43}$ or drowning in rapidly moving water. ${ }^{44}$ Our study does not provide data for these exceptional circumstances as we excluded children involved in motor vehicle or boat incidents and did not identify any child with immersion before drowning or who drowned in rapidly moving water. Therefore for children who drown in winter or under exceptional 
circumstances these data do not support a change in the present recommendation-namely, to continue resuscitation until the patient is rewarmed, with extracorporeal life support if feasible. ${ }^{12} 13$

\section{Unanswered questions and future research}

Given that only 12 children in our study underwent prolonged resuscitation or extracorporeal life support after drowning in winter, future research should focus on the effect of prolonged resuscitation and/or extracorporeal life support on the outcome in children with cardiac arrest and hypothermia after drowning in ice cold water.

\section{Conclusions}

Children with cardiac arrest with hypothermia after drowning have an extremely poor outcome if return of spontaneous circulation is not achieved within $30 \mathrm{~min}$ utes of advanced life support. Good neurological outcome is more likely when return of spontaneous circulation occurs within 30 minutes, especially when the drowning occurs in winter. The findings of this cohort study question the therapeutic value of resuscitation beyond 30 minutes in drowned children with cardiac arrest and hypothermia.

We thank the physicians of the paediatric intensive care units participating in the Stichting Kinder Intensive Care. The participating units were the university medical centres of Amsterdam (AMC, J B M van Woensel and A P Bos, and VUMC, D G Markhorst and F B Plötz), Leiden (LUMC, N A M van Dam and B J Gesink), Nijmegen (Radboud MC, C Neeleman and L G F M van't Hek), Maastricht (MMC, D A van Waardenburg and G D Vos), Rotterdam (Erasmus MC, M de Hoog and D Tibboel), and Utrecht (UMCU, N J G Jansen and A J van Vught). We thank N M Turner, medical director of the Dutch Foundation for the Emergency Medical Care of Children, for his help with the English language.

Contributors: JKK, JJB, and MJA contributed to the study design. JKK and S A van der Linden and I R Prins (medical students at University of Groningen) collected the data. All authors contributed to the analysis, drafting of the manuscript, and approved the final version. All authors had full access to all of the data and can take responsibility for the integrity of the data and the accuracy of the data analysis. JKK is guarantor.

Funding: This research received no specific grant from any funding agency in the public, commercial, or not-for-profit sectors.

Competing interests: All authors have completed the ICMJE uniform disclosure form at www.icmje.org/coi_disclosure.pdf and declare: no support from any organisation for the submitted work; no financial relationships with any organisations that might have an interest in the submitted work in the previous three years; no other relationships or activities that could appear to have influenced the submitted work.

Ethical approval: Not required.

Data sharing: The relevant anonymised patient level data are available on reasonable request from JK.

Transparency declaration: JKK affirms that the manuscript is an honest, accurate and transparent account of the study being reported: that no important aspects of the study have been omitted; and that any discrepancies from the study as planned have been explained.

This is an Open Access article distributed in accordance with the Creative Commons Attribution Non Commercial (CC BY-NC 4.0) license, which permits others to distribute, remix, adapt, build upon this work non-commercially, and license their derivative works on different terms, provided the original work is properly cited and the use is non-commercial. See: http://creativecommons.org/licenses/ by-nc/4.0/.

1 World Health Organization. Factsheet on drowning. www.who.int/ mediacentre/factsheets/fs347/en/index.html

2 Centers for Disease Control and Prevention (CDC). Drowning_United States, 2005-2009. MMWR Morb Mortal Wkly Rep 2012;61:344-7.
3 Venema AM, Groothoff JW, Bierens IJ. The role of bystanders during rescue and resuscitation of drowning victims. Resuscitation 2010;81:434-9.

4 Suominen P, Baillie C, Korpela R, Rautanen S, Ranta S, Olkkola KT. Impact of age, submersion time and water temperature on outcome in near-drowning. Resuscitation 2002;52:247-54.

5 Quan L, Kinder D. Pediatric submersions: prehospital predictors of outcome. Pediatrics 1992;90:909-13.

6 Bohn DJ, Biggar WD, Smith CR, Conn AW, Barker GA. Influence of hypothermia, barbiturate therapy, and intracranial pressure monitoring on morbidity and mortality after near-drowning. Crit Care Med 1986;14:529-34.

7 GrafWD, Cummings P, Quan L, Brutocao D. Predicting outcome in pediatric submersion victims. Ann Emerg Med 1995;26:312-9.

8 Nitta M, Kitamura T, Iwami T, Nadkarni VM, Berg RA, Topjian AA, et al. Out-of-hospital cardiac arrest due to drowning among children and adults from the Utstein Osaka Project. Resuscitation 2013;84:1568-73.

9 Salomez F, Vincent JL. Drowning: a review of epidemiology, pathophysiology, treatment and prevention. Resuscitation 2004:63:261-8

10 Soar J, Perkins GD, Abbas G, Alfonzo A, Barelli A, Bierens JJ, et al. European Resuscitation Council Guidelines for Resuscitation 2010 Section 8. Cardiac arrest in special circumstances: electrolyte abnormalities, poisoning, drowning, accidental hypothermia, hyperthermia, asthma, anaphylaxis, cardiac surgery, trauma, pregnancy, electrocution. Resuscitation 2010;81:1400-33.

11 Szpilman D, Bierens JJ, Handley AJ, Orlowski JP. Drowning. N Engl J Med 2012;366:2102-10.

12 Brown DJ, Brugger H, Boyd J, Paal P. Accidental hypothermia. N EnglJ Med 2012;367:1930-8.

13 Corneli HM. Accidental hypothermia. Pediatr Emerg Care 2012;28:475-82

14 Topjian AA, Berg RA, Bierens JJ, Branche CM, Clark RS, Friberg H, et al. Brain resuscitation in the drowning victim. Neurocrit Care 2012;17:441-67.

15 Tipton MJ, Golden FS. A proposed decision-making guide for the search, rescue and resuscitation of submersion (head under) victims based on expert opinion. Resuscitation 2011;82:819-24.

16 Orlowski JP. Drowning, near-drowning, and ice-water submersions. Pediatr Clin North Am 1987:34:75-92.

17 Orlowski JP. Drowning, near-drowning, and ice-water drowning. JAMA 1988;260:390-1.

18 Suominen PK, Korpela RE, Silfvast TG, Olkkola KT. Does wate temperature affect outcome of nearly drowned children. Resuscitation 1997;35:111-5.

19 Royal Netherlands Meteorological Institute. Climate scenarios. www. knmi.nl/klimaatscenarios/knmi06/gegevens/temperatuur/\#Inhoud 3

20 Dutch Ministry of Infrastructure and the Environment. Database on the qualities of the Dutch surface water.Error! Hyperlink reference not valid. http://live.waterbase.nl

21 Dutch Government. Laws and regulations. www.wetten.overheid.nl/ BWBR0032159/HoofdstukIII/2/Artikel7

22 Idris AH, Berg RA, Bierens J, Bossaert L, Branche CM, Gabrielli A, et al. Recommended guidelines for uniform reporting of data from drowning: the "Utstein style". Resuscitation 2003;59:45-57.

23 Fiser DH. Assessing the outcome of pediatric intensive care. J Pediatr 1992;121:68-74.

24 American College of Surgeons Committee on Trauma, American College of Emergency Physicians Pediatric Emergency Medicine Committee, National Association of EMS Physicians, American Academy of Pediatrics Committee on Pediatric Emergency Medicine, Fallat ME. Withholding or termination of resuscitation in pediatric out-of-hospital traumatic cardiopulmonary arrest. Ann Emerg Med 2014;63:504-15.

25 Atkins DL, Everson-Stewart S, Sears GK, Daya M, Osmond MH, Warden $\mathrm{CR}$, et al. Epidemiology and outcomes from out-of-hospital cardiac arrest in children: the Resuscitation Outcomes Consortium Epistry-Cardiac Arrest. Circulation 2009:119:1484-91.

26 Donoghue AJ, Nadkarni V, Berg RA, Osmond MH, Wells G, Nesbitt L, et al. Out-of-hospital pediatric cardiac arrest: an epidemiologic review and assessment of current knowledge. Ann Emerg Med 2005;46:512-22.

27 Kuisma M, Suominen P, Korpela R. Paediatric out-of-hospital cardiac arrests-epidemiology and outcome. Resuscitation 1995;30:141-50.

28 Sirbaugh PE, Pepe PE, Shook JE, Kimball KT, Goldman MJ, Ward MA et al. A prospective, population-based study of the demographics, epidemiology, management, and outcome of out-of-hospital pediatric cardiopulmonary arrest. Ann Emerg Med 1999;33:174-84.

29 Bierens JJ, Warner DS. Drowning resuscitation requires another state of mind. Resuscitation 2013:84:1467-9.

30 Bierens JJ, Knape JT, Gelissen HP. Drowning. Curr Opin Crit Care 2002;8:578-86

31 Giesbrecht GG. Cold stress, near drowning and accidental hypothermia: a review. Aviat Space Environ Med 2000;71:733-52. 
32 Wanscher M, Agersnap L, Ravn J, Yndgaard S, Nielsen JF, Danielsen ER, et al. Outcome of accidental hypothermia with or without circulatory arrest: experience from the Danish Praesto Fiord boating accident. Resuscitation 2012;83:1078-84.

33 Ruttmann E, Weissenbacher A, Ulmer H, Muller L, Hofer D, Kilo J, et al. Prolonged extracorporeal membrane oxygenation-assisted support provides improved survival in hypothermic patients with cardiocirculatory arrest. / Thorac Cardiovasc Surg 2007;134:594-600.

34 Lee LK, Mao C, Thompson KM. Demographic factors and their association with outcomes in pediatric submersion injury. Acad Emerg Med 2006;13:308-13.

35 Veenhuizen L, Haasnoot K, van Vught AJ, Bierens JJ, Thunnissen BT, Gemke RJ. Submersion in children; the role of hypothermia and development of adult respiratory distress syndrome. Ned Tijdschr Geneeskd 1994;138:906-10.

36 Quan L, Mack CD, Schiff MA. Association of water temperature and submersion duration and drowning outcome. Resuscitation 2014;85:790-4

37 Brugger H, Durrer B, Adler-Kastner L, Falk M, Tschirky F. Field management of avalanche victims. Resuscitation 2001;51:7-15.
38 Kyriacou DN, Arcinue EL, Peek C, Kraus JF. Effect of immediate resuscitation on children with submersion injury. Pediatrics 1994;94:137-42.

39 Eich C, Brauer A, Timmermann A, Schwarz SK, Russo SG, Neubert K, et al. Outcome of 12 drowned children with attempted resuscitation on cardiopulmonary bypass: an analysis of variables based on the “Utstein Style for Drowning”. Resuscitation 2007;75:42-52.

40 Orlowski JP. Prognostic factors in pediatric cases of drowning and near-drowning. JACEP 1979;8:176-9.

41 Layon AJ, Modell JH. Drowning: update 2009. Anesthesiology 2009;110:1390-401.

42 Bierens JJ, van der Velde EA, van Berkel M, van Zanten JJ. Submersion in The Netherlands: prognostic indicators and results of resuscitation. Ann Emerg Med 1990;19:1390-5.

43 Tipton M, Golden F, Morgan P. Drowning: guidelines extant, evidence-based risk for rescuers? Resuscitation 2013;84:e31-2.

44 Eich C, Brauer A, Kettler D. Recovery of a hypothermic drowned child after resuscitation with cardiopulmonary bypass followed by prolonged extracorporeal membrane oxygenation. Resuscitation 2005;67:145-8

(C) BMJ Publishing Group Ltd 2015 